\title{
Sarah Kay, Terence Cave, Malcom Bowie, A short story of French literature, New York
}

\section{Luigi Luison}

\section{Q OpenEdition}

1 Journals

\section{Edizione digitale}

URL: https://journals.openedition.org/studifrancesi/40103

DOI: 10.4000/studifrancesi.40103

ISSN: 2421-5856

\section{Editore}

Rosenberg \& Sellier

\section{Edizione cartacea}

Data di pubblicazione: 1 décembre 2004

Paginazione: 438

ISSN: 0039-2944

\section{Notizia bibliografica digitale}

Luigi Luison, «Sarah Kay, Terence Cave, Malcom Bowie, A short story of French literature, New York», Studi Francesi [Online], 143 (XLVIII | II) | 2004, online dal 30 novembre 2015, consultato il 19 mai 2021. URL: http://journals.openedition.org/studifrancesi/40103; DOI: https://doi.org/10.4000/studifrancesi. 40103

Questo documento è stato generato automaticamente il 19 mai 2021.

\section{(c) (1)}

Studi Francesi è distribuita con Licenza Creative Commons Attribuzione - Non commerciale - Non opere derivate 4.0 Internazionale. 


\title{
Sarah Kay, Terence Cave, Malcom Bowie, A short story of French literature, New York
}

\author{
Luigi Luison
}

\section{NOTIZIA}

SARAH KAY, TERENCE CAVE, MALCOM BOWIE, A short story of French literature, New York, Oxford University Press, 2003, pp. 344.

1 Questa breve storia della letteratura francese, che offre alcuni estratti di testi letterari accuratamente selezionati dagli Autori, è suddivisa in tre parti, organizzate cronologicamente: una prima parte dedicata al Medioevo fino al 1470, una seconda che arriva sino alla Rivoluzione Francese, e una terza che riguarda l'età moderna (1789-2000).

Ogni sezione è preceduta da una breve introduzione che illustra il contesto letterario evidenziandone le peculiarità attraverso le tematiche dei principali autori.

3 Questo viaggio attraverso la tradizione letteraria francese inizia con un tentativo di definizione del concetto stesso di letteratura; concetto che, nascendo da una percezione contemporanea, legge la letteratura medioevale come «d'immaginazione» che va riconnessa, tuttavia, alle altre arti - come ad esempio la musica - e passata a un vaglio filologico che consenta ai componimenti in langue d'oc e langue d'oil di esprimere il loro potenziale linguistico.

Una parte importante del discorso di KAY, CAVE e BOWIE è l'analisi del linguaggio letterario che viene visto come «defamiliarizzante», e che, in quanto tale, «rende estraneo anche il mondo così come noi lettori lo percepiamo». Il tentativo degli Autori, in un'ottica di ermeneutica letteraria, è di stabilire un nuovo e più dinamico approccio con la tradizione letteraria della Francia. 
5 Occorre sottolineare che ogni periodo trattato in questo volume mette in evidenza alcuni esponenti ed alcuni movimenti letterari a scapito di altri, e includendo, per contro, diversi testi che oggi sono conosciuti solo dagli specialisti della materia. Gli Autori hanno impostato il volume in questo modo poiché ritengono che la tradizione letteraria francese sia importante non solo per quanto riguarda la qualità delle opere realizzate, bensì per la continuità con cui numerose opere sono state prodotte in un arco di tempo che abbraccia otto secoli ed anche di più. Proprio per questo motivo si giustifica l'ampio spazio che viene dedicato, nel testo, al periodo medievale rispetto al periodo moderno.

Il volume si chiude con una ricchissima bibliografia e con una utilissima sezione in cui vengono consigliati testi specializzati a chi desideri approfondire un particolare periodo letterario francese. 